\title{
How advertisers create affinity between destinations and American and British audiences: towards a theoretical framework
}

\author{
Eli Avraham \\ University of Haifa, Israel
}

The purpose of this paper is to propose a theoretical framework that explores how advertisers attempt to establish affinity between destinations and British and American audiences. The proposed framework consists of four spheres, five techniques, two message strategies and four means. This framework will be presented through a qualitative content analysis of 103 cases, selected from almost 2500 print advertisements and YouTube videos. The print advertisements were published in four major tourism magazines between 2007 and 2019. Besides the theoretical contribution, a study of audience affinity that analyses many cases might be helpful for marketers and policy makers, giving them ideas of how to reach and touch specific audiences.

Keywords: tourism advertisements, destination marketing, affinity, message strategies

\section{INTRODUCTION}

The process by which visitors choose a particular destination consists of factors related to the tourist's personality and his/her preferences as well as to the destination's characteristics, including location, type of tourism and cost (Asseraf/Shoham 2017; Souiden et al. 2017; Nes et al. 2014; Fyall et al. 2019). While audience affinity towards a particular destination has been widely researched, there is little research or theoretical framework regarding advertisers' efforts to create affinity between a destination and a specific target audience (Asseraf/Shoham 2017; Kim/Lehto 2013). Most studies on affinity were demand-driven, and rarely discussed the supply side for marketers/advertisers and what they should do to create the desired affinity (Asseraf/Shoham 2017; Kim/Lehto 2013; Souiden et al. 2017). This lack of research concentrating on the advertisers' side is surprising in light of previous empirical studies that identified factors causing an affinity between a certain target audience and destinations (Souiden et al. 2017; Nes et al. 2014). We would, therefore, have expected marketers to have used this knowledge to make sure their advertisements (ads) contain these factors in order to increase the audience's affinity for their destination. As a result, we would like to focus this study on various factors that can be used by advertisers to create affinity with a certain audience. The main research question is: Which spheres, means and techniques were used by destination marketers in their ads to develop affinity messages for American and British audiences?

This study proposes a theoretical framework throughout a qualitative content analysis of 103 cases, selected from almost 2500 print ads and YouTube videos, and proposes spheres (national, geographical, economic, cultural), techniques (similarity, proximity, familiarity, cultural symbols/heroes/brands, patriotism/nationalism), means (slogans, 
visuals, text, human models) and message strategies. The print ads that were analysed were published in four major tourism magazines between the years 2007 and 2019: the United States (US) and United Kingdom (UK) editions of Condé Nast Traveler/ Traveller and National Geographic Traveler/Traveller. In addition to the theoretical contribution, this multi-case study might be helpful for marketers and policy makers, giving them ideas of how to reach specific audiences.

\section{THEORTICAL BACKGROUND}

This paper is comprised of several sections. First, studies related to destination image, projected image and personality, affinity theory and affinity creation by marketers are reviewed. Section 3 then introduces the research question and methodology. Section 4 relates the findings of the analysis, and Section 5 offers a discussion and conclusions.

\subsection{Destination image, projected image and personality}

Authors distinguish between 'destination image' (DI) and 'projected image' (PI). According to Stepchenkova and Li (2014), DI includes the attributes of a destination and the audience's perceptions that characterize it (Lai et al. 2020). Boulding (1956) defines an image as the sum of the cognitive, affective and evaluative characteristics of a place, or an inherent self-perspective thereof. Baloglu and McCleary (1999) present a general framework of destination image formation developed from previous literature; in addition, Echtner and Ritchie (1993) offer a framework that suggests how to measure destination image. Projected image, on the other hand, 'is formed through promotional activities of the DMOs [destination management organizations] and those in the tourist industry as well as news and information about the destination from multiple sources' (Kim/Lehto 2013: 120). The efforts of decision makers and marketers to build a certain image and to attach values, narratives and perceptions to specific destinations are made using various tools, such as ads, public relations (PR), digital and direct marketing, and social media (Fyall et al. 2019; Ketter/Avraham 2021; Avraham 2021).

Over the years researchers have claimed that consumers were treating brands and destinations like people (d'Astous/Boujbel 2007), and that to gain a competitive advantage marketers needed to define their target audience and align the audience's characteristics to the 'personality' of the marketed product (Kim/Lehto 2013). According to d'Astous and Boujbel, the personality perspective fits well with the self-image congruence theory, which proposes that people prefer objects whose psychological characteristics are congruent with their own psychological characteristics. Research has provided empirical evidence that well-established and well-communicated brand personality influences consumer preference and usage, determines product evaluations, evokes emotions in consumers and increases levels of loyalty to a brand (Kim/Lehto 2013; Bekk et al. 2016).

\subsection{Affinity theory}

As mentioned, up to this point we have dealt mainly with destinations' 'projected image'. We would now like to discuss the concept of 'affinity' from the consumer's point of view, where the concept was initially developed, and then discuss it from the advertiser's perspective. Affinity theory assumes that consumers are more attached to 
brands that they perceive as being similar to themselves. Asseraf and Shoham (2017: 375 ) claim that, "in general, consumer affinity is considered a positive attitude toward a specific focal country'. Nes et al. (2014: 774) define consumer affinity as 'feelings of liking and fondness for a specific foreign country'. Citing Hartz et al. (2005), Oberecker et al. (2008: 24) mention that sociology literature refers to the term 'affinity' as 'forces that cause one person ... to be drawn to, and seek a relationship with, another ... based on the latter's attributes'. Oberecker et al. explore several bases for consumer affinity - such as lifestyle, culture, scenery, politics and economics. Nes et al. (2014) claim that affinity derives from several categories: culture, arts and history, people, landscape and climate, food, politics, family and friends, and travel. Souiden et al. (2017) state that most studies of DI focus on functional attributes, including landscape/surrounding nature, cultural attractions, nightlife and entertainment, shopping facilities, residents' receptiveness and safety.

According to Nes et al. (2014: 774-775), 'people who develop affinity toward a foreign country may do so because they identify with the country's culture, they consider the country to be one of their in-groups because they find it attractive, or find that their identification with the country contributes to their social identity'. According to Kotsi et al. (2018), the key is not only creating positive emotions but also creating emotional bonds with customers that result in a positive attitude. In addition, they claim that it is not necessary to experience the product or place in order to have these 'positive emotions'. There is a need to find emotional connections, which can be achieved by using various factors such as history, heritage and culture.

Many empirical studies reinforce the proponents of affinity theory and find that similarities between audience characteristics and product characteristics create an affinity for the product among the audience (Nes 2019; Cheung/Saha 2015). In other words, the perception of similarity between audience members and product also elicits positive feelings among the target audience regarding the product (Asseraf/Shoham 2017). Hence, it seems logical that tourism marketers should concentrate their efforts on displaying the similarities between the audience and the destination's characteristics and activities as this might increase the likelihood of its preference over other destinations (Avraham/Ketter 2008). Despite this, there are almost no studies on advertisers' efforts to create this sense of similarity that is a key factor in creating affinity between audiences and destinations.

\subsection{Affinity creation by marketers}

Given that the relationship between destinations and audience is mutual, it is necessary to examine how marketers present their destinations in order to attract tourists. In the academic literature there are analyses of individual branding and marketing case studies (Rinaldi/Beeton 2015; Hudson/Ritchie 2009) and multi-case studies. Since the present study used a large number of cases, we would like to focus our discussion on this kind of analysis. We found two kinds of multi-case study. The first analyses which of the destination's characteristics/activities appear in the ads (Brito/Pratas 2015; Kotsi et al. 2018). For example, First and Avraham (2009), who studied the use of the American myth in marketing products in Israeli ads, offer the 'performing the global/performing the local' model, which includes four spheres and their variables to market a product: (1) cultural (products, local and international popular heroes and brands); (2) national (flag, language, political leaders); (3) geographical (borders, landscapes, sights); (4) economic (technology, currency, investments). 
In the field of destination marketing, Kotsi et al. (2018) suggest several categories that marketers use to present a place: lifestyle, celebrations and festivals, artefacts and daily life, wildlife and landscape, and occupations. While most of the research looks at the affinity created from the consumers' point of view, First and Avraham's model analyses the creation of affinity from the advertisers' point of view. We would therefore like to adopt their model for our theoretical framework.

The second kind of study analyses how marketers create affinity between a destination and specific target audiences (Avraham/Ketter 2008). Here marketers do not 'just' present what their destination can offer; they also try to create a positive emotional connection between a destination and a target audience. There are several examples of this type of campaign. Tunisia, after the Arab Spring, emphasized its new values - freedom and free choice - to market itself to Western tourists with the slogan 'Free to live it all' on the basis of the similarity of values. This technique was also used in Egypt's campaign Masr Kariba ('Egypt is near') aimed at the Gulf states in 2014, which emphasized the similarity between Egypt and the Gulf states in religion, language and culture (Avraham/Ketter 2016). Zimet (2017) presented several campaigns centred on highlighting the similarity and proximity between the characteristics and values of countries and foreign audiences. For example, the US campaign in the Muslim world after 9/11 emphasized the 'shared values' of the two sides.

Avraham and Ketter $(2008 ; 2016)$ offer 'audience-focused strategies' that marketers adopt in order to reach out to certain target audiences. In their analysis, they expand the discussion on ways to create affinity apart from emphasizing the similarly of values, and offer four other techniques:

1. Cultural symbols, heroes and brands. The destination is connected to the audience's cultural symbols, heroes and brands - for example the use of a famous German football player to market the UK in Germany.

2. Proximity. The cultural or geographic proximity of the destination to the audience is shown.

3. Patriotism/nationality. Here patriotic feelings are used to increase local tourism by making the connection between a destination and the national narrative and heritage.

4. Familiarity - mentioning the fact that the audience is already familiar with the destination from previous visits.

We would like to include these four techniques as well as similarity in our theoretical framework for creating affinity.

\subsection{The theoretical framework}

To build the main theoretical framework (Figure 1), we adopted two models as each one focuses on different factors. First, as mentioned, we adopted the "performing the global/performing the local' model (First/Avraham 2009), which offers four spheres that advertisers used while promoting foreign products (national, geographical, economic, cultural). Second, we used Avraham and Ketter's (2008) 'multi-step model for altering place image', which offers five techniques (similarity, proximity, attachment to cultural symbols/heroes/brands, familiarity, patriotism/nationalism) that marketers used to connect a place to specific audience. 


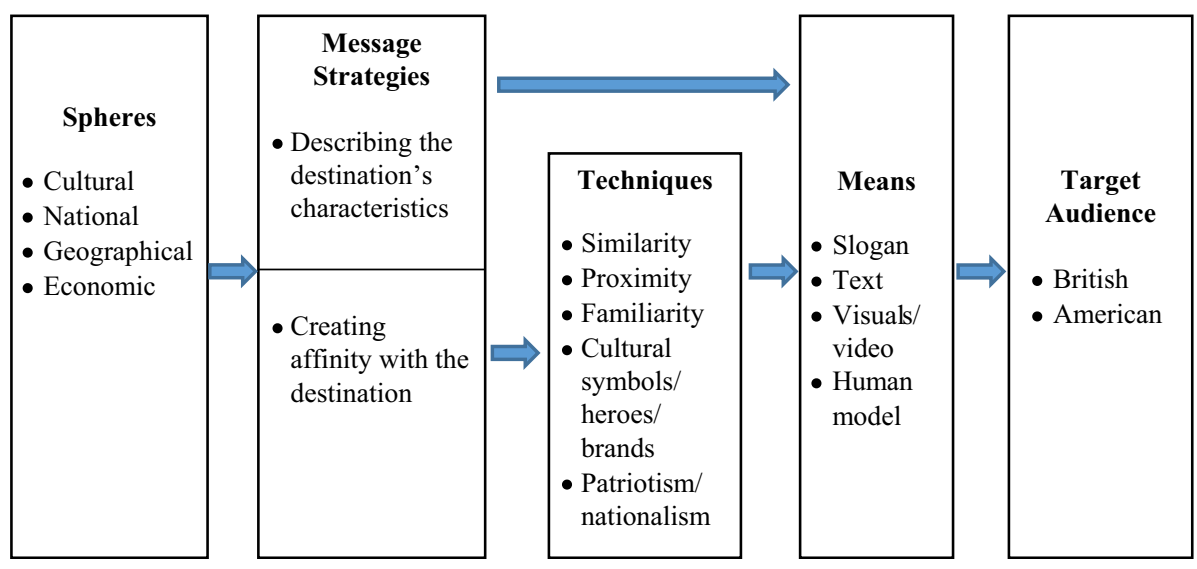

Figure 1 Factors involved in creating affinity between destinations and target audiences in tourism ads

The assumption embedded in our model is that advertisers make a strategic decision about the members of the target audience they want to reach (American and British in our case) and then try to persuade them to visit a destination. The decision, as can be expected, affects the rest of the decision-making process regarding the advertisements. In the first stage the advertisers decide which activities or characteristics in which sphere they want to emphasize - for example, those related to cultural or geographical characteristics. Then a decision has to be made regarding the message strategy: will they choose one that only describes what exists in the destination or one that creates an affinity for the target audience. If the decision is to only describe what exists in the destination, advertisers go directly to the decision about the tool that will be used (slogans or visuals, for example). If the marketers choose to try to create affinity, they then decide which of the five techniques will be used (similarity or proximity, for example) and only then decide which means will convey the message strategy.

Our model in Figure 1 offers, for the first time, two kinds of message strategy: (1) describing the destination's characteristics in which the ads try to describe the place's reality, including visuals and text messages emphasizing the destination's characteristics such as scenery, activities or facilities; (2) creating affinity with the destination, where the ads include visuals and text messages that aim to create affinity with a certain audience - 'The UK and US share the same history and heritage, come visit the UK.' In the first message strategy the ad 'just' mentions what kind of characteristics and activities the destinations have to offer in a certain field for the general public; the second message strategy attempts to create affinity with a particular, defined audience (in our example, American visitors).

The 'creating affinity' message strategy was executed while adopting one of five techniques:

1. Similarity was used to show similarity in language or heritage between the marketed destination and the UK or the US ('We have fish and chips here').

2. Proximity was used to show various kinds of proximity to the UK or US, such as in geography ('Only two hours from New York'). 
3. Employing American or British cultural symbols/heroes/brands (the use of an American actor to promote Albania).

4. Patriotism/nationality was used to connect local destinations to the national narrative and heritage ('Come see where our nation started').

5. Mentioning former familiarity between the audience and the destination ('Fall in love with New Orleans all over again').

These five techniques prove effective in building affinity from the consumer side (Bekk et al. 2016; Walters/Mair 2012; Nes 2019; Nes at al. 2014; Oberecker et al. 2008; Souiden et al. 2017; Asseraf/Shoham 2017; Avraham/Ketter 2008; Walters/ Clulow 2010). Relying on these studies and others on arousal in advertising (Jiang et al. 2020) there is a strong base to believe that use of these techniques in advertising also has the potential to stimulate positive emotions toward destinations. As our study is not empirical, we cannot claim that use of a particular strategy in the ads definitely created an audience's affinity with the destination. Nevertheless, we believe that the findings of previous exploratory and empirical studies that we present, and which identify factors that have the potential to create affinity on the audience side, give us a strong base to believe that certain message strategies used in ads will be much more effective than others in creating the desired affinity.

After selecting the target audience, the spheres and the appeal strategies, marketers need to choose the means by which the affinity with the target audience will be created. Here it is possible to create affinity using slogans, text, visuals/video or human models:

1. Slogan - a short text that is striking or memorable and includes the essence of the marketing message.

2. Text - used to describe the destination's attributes, location, advantages and attractions.

3. Visuals and video - these can serve not only as a means to describe a place as a written text but also to convey a message to a certain audience. An example would be the use of the American flag in the campaign to attract Americans back to New York after 9/11.

4. Human models - the models used in the ad can also be a tool in creating affinity. On many occasions advertisers try to use models who look like the target audience (Kim/Lehto 2013; Avraham/Ketter 2008; 2016; First/Avraham 2009).

\section{METHODOLOGY}

The main research question in this study is: Which spheres, means and techniques were used by destination marketers in their ads to develop affinity messages for American and British audiences?

\subsection{Qualitative content analysis}

This study utilizes qualitative content analysis, based on a semiotic interpretation of texts. The qualitative approach is especially useful for studies attempting to explain social interaction in general and makes use of inductive reasoning, generalizing from the social reality to a more comprehensive theory (Tuchman 1991). This method is based on a thorough understanding of the analysed units and examines the common signifying process. Researchers using this method believe that texts reveal general 
discourse patterns (Pauly 1991) through the appearance of motifs, labels, definitions, logos, symbols, visuals, slogans and generalizations presented in the ads as exclusively characterizing a specific place or destination (van Dijk 1988). The qualitative content, which can be analysed by both language and visuals, is a popularly used method in studies of place marketing, advertising and branding (De Jager 2010; O’Barr 1994; Brito/Pratas 2015; Avraham/Ketter 2016).

\subsection{The sample}

We analysed print ads and videos collected from two sources: (1) four US/UK-based popular tourism magazines - the US and UK editions of Condé Nast Traveler/Traveller (CNT) and National Geographic Traveler/Traveller (NGT); (2) YouTube.

\subsubsection{US/UK-based popular tourism magazines}

Condé Nast Traveler (US) first appeared in 1987 and Condé Nast Traveller (UK) began in 1997; they were combined in 2018. The US National Geographic Traveler (NGT) first appeared in 1984, and the UK edition debuted in 2010. These magazines' main target audiences are the American and British markets. We analysed their ads from the years 2007-2019 (with the exception of the UK edition of National Geographic Traveller, which we began analysing from 2010). Six issues were sampled in the first, middle and last three years of this period (2007-2009, 2012-2014, 2017-2019). Two random issues of the other years were also analysed (2010-2011, 2015-2016). A total of 2080 ads were examined, 66 of which were chosen as the best examples to illustrate the theoretical framework's components. Since we found several examples for each of the theoretical framework's factors, we will only present here a small number that best illustrate certain spheres, techniques, message strategies and means.

\subsubsection{YouTube}

To find YouTube videos to include in our analysis, we inserted the words ' $\mathrm{X}$ (name of a country) tourism ad/advertisement/campaign/commercial' and ' $X$ (name of a country) tourism ad to UK/US market', according to the names of the 192 countries on the United Nations website - for example, 'Afghanistan tourism ad', 'Albania tourism ad' and so on down the list (ads are marked \#1-42 in Appendix 1).

In the course of looking for tourism ads that were distributed by the 192 countries, we discovered 450 that comprised our sample. From these ads' messages, content and language (for example if they included sentences such as 'We are only 3 hours from the US' or 'Direct flights from London') we determined whether they were aimed at the American or British market. If so, they were analysed. Videos that promoted investments were also included if they mentioned tourism - for example 'Croatia tourism: the beauty of investment' (\#17). We ended up with 42 videos that were the best examples to illustrate the model's components (Appendix 1).

When examining the ads and YouTube videos, the researchers looked for the appearance of the spheres, message strategies and techniques in slogans, symbols, visuals, human models and text. The idea behind analysing print ads in addition to YouTube videos was to see if there are differences between the two mediums, as 
was done by previous advertising studies (Avraham 2020). The ads included in the analysis were those produced for destinations by official bodies (national/local tourism offices, DMOs and national tourist organizations (NTOs), ministries of foreign affairs, etc.) or recognized organizations or associations such as hotel chains or airlines. As previous studies in place marketing were mainly individual case studies, focused on marketing efforts of specific destinations (De Jager 2010; Hudson/Ritchie 2009), there has been a shortage of broad-based studies that analyse numerous cases (Mair et al. 2016). By using a large number of cases this paper aims to reach typologies, general conclusions and insights in order to build a theoretical model. As Cahill (1997: 12) claims, 'Typologies can be an important method of theory building, not just a descriptive tool.'

American and British audiences were selected for a number of reasons. Although there are differences between these audiences in various areas, they have much in common. The two countries share the Anglo-Saxon culture; they have strong historical, cultural and economic ties; and their populations are both considered to have economic means and significant demand for domestic and foreign tourism. At the same time their major cities, New York and London, are global diplomatic and economic centres, as well as housing many embassies, consulates and DMOs engaged in domestic and foreign tourism marketing (New Yorkled 2016). For these reasons, we expected that many destinations in the world would publish ads in the tourism magazines aimed at these two target audiences. An analysis of a large number of ads will provide us with the data to form the basis for building the theoretical framework. It is important to mention that we did not analyse the differences between ads addressing American and British audiences.

\section{FINDINGS}

In the findings section we would like to present the four spheres: cultural, national, geographical and economic, each of which includes various components.

\subsection{The cultural sphere}

The cultural sphere includes various components: cultural products and heroes, music, sport and cuisine. Several studies that explore the bases for consumer affinity find that culture is central (Nes et al. 2014; Souiden et al. 2017).

\subsubsection{Culture and art}

We would like to present two message strategies regarding this component.

\section{(a) Describing the destination's characteristics}

In this strategy marketers mention the destination's culture and art components in general. Some examples: Pasadena - Art, culture and more (NGT 10/2008); Holland Visit centuries of art and design (NGT 1/2009); and Viva Albuquerque, viva culture (NGT 4/2008). The cultural component is also promoted by using visuals such as photos of concert halls and museums. 


\section{(b) Creating affinity with the destination}

While in the previous strategy marketers mainly mention what the place has to offer culturally, here there is an attempt to create affinity with a specific target audience using cultural symbols, brands and heroes. The use of cultural heroes to promote a place is a familiar strategy in place marketing as advertisers try to bask in the reflected glory of celebrities who are connected to the marketed destination (Avraham/Ketter 2016). We found extensive use of actors in the ads. For example, Barcelona's marketers used the success of the movie Vicky Cristina Barcelona in the US to attract American tourists: 'On August 15 see "Vicky Christina Barcelona," the next day, book your trip to Spain' (NGT 5/2008), with the actors' photos in the ad's centre. The actor Paul Hogan ('Crocodile Dundee', \#1) was used to promote Australia to American tourists, and Kylie Minogue, an Australian singer who lived in the UK, was used to attract British tourists to Australia (\#4). Portugal used the British actor James Palmer to appeal to the UK market (\#29), and the UK used Dame Judi Dench and actors from the Harry Potter films to promote local tourism (\#35). Other actors used to attract American tourists to foreign and local destinations were Johnny Depp (St. Petersburg, Florida; CNT 3/2009), James Belushi (Albania, \#2), Nicolas Cage (Washington, DC; NGT 1-2/2008), Jim Carrey (Colombia, \#20), Sylvester Stallone (Bulgaria, \#23) and Rihanna (Barbados, \#31).

\subsubsection{Music}

Music attracts visitors to destinations as they come to experience and enjoy festivals, shows, museums and the homes of musicians. We find two strategies regarding the music component.

\section{(a) Describing the destination's characteristics}

Here the marketers use music in general with a focus on specifics related to the destination's music industry, such as a concert hall, classical orchestra or street musicians. We found many examples of musical events and related facilities that were used as an incentive to attract tourists. For example, Atlanta emphasized its night life: 'Club Hopping ... Festival Following ... and music loving-shopaholic' (CNT 3/2008); and New Orleans used its music component: 'All Jazzed up and ready to celebrate ... Catch contemporary Jazz' (CNT 7/2007); 'You don't need a radio to hear our music. You need a map. We have great festivals all over the state' (NGT 4/2008).

\section{(b) Creating affinity with the destination}

While in the former strategy musical events and facilities were mentioned, here we find ads where the marketers try to connect one of the destination's musical components to British and American audiences. In order to attract tourists from the UK in general, and from Scotland in particular, Bulgaria published an ad where the main visual was a bagpipe band from Scotland and the text was: 'This summer I'm leading the band.' The campaign aimed to use the Bulgarian 'Battle of the Pipes' music festival to create affinity between UK visitors and Bulgaria (NGT 1-2/2012). Croatia 
similarly presented a visual of bagpipers in an ad geared to the UK market (\#17). The use of this music component can also attract local tourists. For example: 'Live from the birthplace of America's music - Mississippi' (NGT 3/2009), with a visual of the place. In addition, we found the use of cultural heroes/brands such as singers and musicians who are familiar to the target audience. Louisiana used many of its native musicians who are familiar to the American audience (such as Tim McGraw, Terrance Simien and Terence Blanchard) in numerous campaigns (NGT 3-4/2009).

\subsubsection{Food/cuisine}

Food and local cuisine attract visitors to places (Lai et al. 2020). In this component we can also see two kinds of strategy.

\section{(a) Describing the destination's characteristics}

Here the marketers use food and cuisine to attract tourists by means of slogans and visuals. For example, California proclaimed 'Welcome to California, the land of wine and food' (CNT 9/2009), and Georgia exclaimed 'You might visit Savannah today for the fine food and charming atmosphere' (NGT 3/2009). In 2009, Japan ran the 'A taste of Japan' campaign (NGT 4/2009), offering 'savoury street food to premium sake tasting, multi-course meals, cutting-edge nouvelle cuisine' (CNT 1/2009). Korea ran a similar campaign: 'Eat Korea ... come and enjoy one of the world's healthiest and tastiest cuisines in one of the world's coolest countries' (NGT 1-2/2017).

\section{(b) Creating affinity with the destination}

In this strategy the cuisine component is not only mentioned but used in conjunction with the cultural heroes/brands technique as a means to connect the destination to a certain audience. A good example is a video in which Canadian Prime Minister Justin Trudeau shared a meal at a Canadian restaurant with the American Top Chef winner Kristen Kish (\#3). In the video, Trudeau and Kish talked about emerging food trends across Canada, Canadian wine and the cuisine one encounters while travelling the country. They also mentioned similarities between the multicultural Canadian and American kitchens. In this case the ad did not just mention the destination's culinary characteristics, but tried to create an affinity with the American audience. Other examples are Louisiana, which used a visual of the American chef Emeril Lagassé, who owns a restaurant in New Orleans (CNT 4/2007); and Australia, where a video focused on British tourists and mentioned that 'We know that you love fish and chips and your curries' (\#4).

\subsection{The national sphere}

The national sphere consists of several components, including language, politicalhistory/heritage and people, flag, and political system/politicians.

\subsubsection{Language}

The language of ads plays a major role in reaching any target audience; an ad in French trying to attract American tourists to France would probably not be useful. 
Most of the ads promoting destinations around the world are in English as this language is international.

\section{(a) Describing the destination's characteristics}

Since the tourism journals that were analysed for this study were aimed at Englishspeaking audiences, all the ads analysed were in English. As a result, English was used to present the destinations' characteristics in all of the four spheres. While applying this strategy there is a need to distinguish between two kinds of destination, British/American and others. We can say that each ad for foreign destinations used this strategy.

\section{(b) Creating affinity with the destination}

For non-English speakers, a country's use of English in ads can be considered a way to create affinity because the destinations' marketers make the effort to reach a foreign audience while tailoring the use of English for that foreign market. Here we would like to go beyond the use of English in ads and describe how marketers emphasize the popularity of the target audience's language in their destinations to create affinity with English-speaking audiences. Examples include 'Holland - Did you notice that I am speaking English? We all do' (\#5); Belize, the only Englishspeaking country in Central America (\#13); and Croatia - '49\% English speakers' (\#17). Accent can also be a tool to create affinity. In a campaign for Las Vegas that ran in the UK, the slogan was 'Visit a place where your accent is an aphrodisiac' (Berns 2015); and in South Africa a narrator with a British accent was used in its tourism ad (\#32). Similarly, accent was highlighted in an Australian ad to attract American tourists: Paul Hogan states rather humorously, 'We talk the same language, although you like to have a funny accent' (\#1). Australia used the same technique in a video focused on British tourists: 'We speak your language, except for the vowels' (\#4). In these campaigns, the marketers played on the language and accent of British and American tourists to present proximity, which in turn creates affinity between potential tourists and various destinations.

\subsubsection{Political-history/heritage}

This component is central due to the great interest of tourists in history and heritage.

\section{(a) Describing the destination's characteristics}

Here ads present what the destination has to offer regarding history and world heritage to general audiences. Examples include Aqaba, Jordan - 'where history has been carved from the rock itself' (NGT 9/2014); South Korea - 'Stopover in Seoul: a dynamic blend of the ancient and modern' (NGT 5/2014); Orissa, India 'Every stone tells a story. The temples, monasteries and shrines stun you with the brilliance of a magnificent Heritage 10,000 years old' (NGT 1-2/2012); and Germany - 'Relive defining moments of history in Germany' (NGT 9/2009), a campaign based on the 20th anniversary of the fall of the Berlin Wall. 


\section{(b) Creating affinity with the destination}

In the process of creating affinity, foreign destinations use the political-history/heritage component. Destinations try to create an affinity with British and American tourists while the focus is on the similarity or proximity in a political-history context. For example, an ad for St Helena mentioned that the island's 4000 residents 'hail from a melting pot of British settlers' (NGT 7-8/2014). Similarly, a Jamaican video mentioned that 'Jamaica has a special place in the hearts and mind of the British' (\#24); and Germany offered a 'Royal welcome to Germany: The connection between Great Britain royal house goes back many years' (NGT 3/2015). Another fine example of creating affinity was an ad for the Italian Alps with British visitors in mind: '1864-2014: 150 years of British Alpinism on the mountains of the Trentino region. Follow the Victorian pioneers' tracks and write the live diary of your journey' (NGT 7-8/2014). In this component the message strategy to create destination affinity used proximity and similarity techniques. Destination marketers also tried to create affinity with domestic visitors using the nationalism technique, for example: 'Culpeper, VA - Our history is the history of America' (NGT 5-6/2009); 'Saratoga - Where American history lives on' (NGT 5-6/2009).

\subsubsection{People/inhabitants}

Here marketers use locals or foreigners to create affinity between a certain place and the target audience. As Nes et al. (2014: 776) note, 'Affinity towards the people of a country can translate into affinity towards the country itself.'

\section{(a) Describing the destination's characteristics}

Here marketers highlight appropriate positive traits among the inhabitants that may be welcoming or friendly. We found that marketers used this component in various ways. The 'simple' way was to present a photo of a 'typical' inhabitant. For example, in Myanmar's ad the main image was of a young local man on a small boat (NGT 5/2014). Another way was to emphasize the locals' positive characteristics. Examples include: Finland - 'Feel the friendliness' (CNT 1/2007); the Philippines 'Everybody, and absolutely everybody, knows how to smile and have fun' (\#4); and Egypt's \#peopletopeople ad (\#39).

\section{(b) Creating affinity with the destination}

Here we found ads also using people, but presenting people who look like members of the target audience. Avraham (2016) presents this strategy using a campaign to attract tourists to Egypt after the Arab Spring in which most of the models were white and of Western appearance. It seems as though the advertisers did this to 'prove' that Westerners come to visit Egypt without fear and that other Westerners should do likewise. A similar example was found in a video commercial for Tunisia (\#27), which also featured white actors. A Chilean ad featured a visual of two local women wearing traditional clothes, together with two white/Western tourists and the slogan: 'If you want to experience ancient Mapuche culture in Araucania come to Chile' (NGT 5/2014). A Singaporean ad featured two Western/British models (NGT 3/2015), and in a 
Panamanian ad there was a visual of a blonde woman laughing along with traditionally clad local women (CNT 7/2009). Several countries put American models at the centre of their ads in order to show what a tourist can experience in their countries (Laos, \#9; Holland, \#8; Thailand, \#10; Indonesia, \#14; Zambia, \#37).

In addition to presenting models who look like members of the target audience and who seem to be enjoying the place, destinations marketers also emphasize how members of the target audience admire or feel attached to the marketed destination. For example, under the headline 'Country of birth: USA, Motherland: India' was a visual of an American woman practising yoga and falling in love with India (NGT 1-2/ 2009). In a Brazilian ad with a visual of American women the text read 'Dominique Benz, from the United States, another fan of Brazil' (CNT 8/2008). There were many other examples: Tunisia used photos of two British tourists - 'Charlotte, UK' and 'Evan, UK' - with the British flag (\#36); Curaçao's ad had the narrator mention a letter in a bottle they received 'from Larry, Des Moines, Iowa' (\#22). Two techniques were used here: similarity between those who visited the destination and audience members; and proximity - a previous close connection - between the place and audience members.

\subsection{The geographical sphere}

The geographical sphere and natural environment are central in presenting a place and appealing to various target audiences (Kotsi et al. 2018). The geographical component includes scenery, sights, climate and activities as well as the destination's location, proximity and accessibility.

\subsubsection{Scenery, sights and activities}

The first element of the geographical sphere is related to the destination's scenery and activities.

\section{(a) Describing the destination's characteristics}

Here the marketers present what the destination has to offer regarding scenery and activities while using text, slogans and visuals/photos. For example, a destination's 'content' (such as beaches, mountains and wildlife) was promoted with text/slogans: Slovenia - 'Looking for unspoilt nature? Alpine lakes and mountain peaks? Outdoor activities and cultural festivals? Historic cities and world-class wines?' (NGT 12/ 2012); Botswana - 'An indulgence of wildlife and breath-taking sceneries' (NGT 12/2012); 'Borneo's odd wildlife up close' (NGT 9/2014).

\section{(b) Creating affinity with the destination}

In this strategy we found ads that claimed similarity between the destination's activity/scenery and those familiar to the target audience. Presenting similarity is a well-known technique to create affinity (Fourie/Santana-Gallego 2013). For example, as part of the 'Incredible India' campaign, India published an ad with the headline 'Scotland awaits in India' (NGT 1/2017); the visuals showed scenery resembling 
views in Scotland and the text proclaimed an 'Abode of clouds, enchanting lakes, lush greenery, scenic waterfall, vibrant culture' (NGT 1/2017). A Saudi Arabian ad showed a visual of a desert with the headline 'This is not Arizona, this is Saudi' (CNT 11/2019). Employing a variety of visuals, Lebanon used a similar campaign (\#28) which mentioned that it had scenes reminiscent of London, Las Vegas, Paris and other cities. A Japanese promotional campaign was found that added the slogan 'Japan. The other long island' to a visual of a long island (NGT 4/2009). Using this strategy, marketers suggest to the target audience that the destination has 'familiar' scenery (Fourie/Santana-Gallego 2013). The familiarity technique in the geographical sphere was also expressed in ads such as 'Mexico, the place you thought you knew' (\#37) and 'Come fall in love with New Orleans all over again' (NGT 4/2008). Here the marketers emphasize previous relations between audience and destination, based on past experiences.

\subsubsection{Geographical location, proximity and access}

The second component of the geographical sphere is the destination's proximity to the audience and accessibility; tourists are usually concerned about flight availability and the long distances they might have to undertake to reach a destination. As a result, this component includes information that is related to the destination's location and accessibility.

\section{(a) Describing the destination's characteristics}

Here the marketers just indicate the place's location in various ways using text, slogans and visuals. For example, an ad for St Helena mentions the island's location ' $15^{\circ} 15^{\prime} 36.91 "$ S, 5 43' 0.38" W' (NGT 9/2014) - and an ad for the Azores stated: 'Azores are located in the Atlantic Ocean' (NGT 10/2019). The location of the destination can be also mentioned in a slogan, such as 'Portugal - Europe's west coast' (NGT 9/2014). Visuals were also used in these ads. In an ad for Kosovo there was a map where the country's location was emphasized (\#11), and in Sierra Leone a video showed the country being 'on the West coast of Africa' (\#25). Similar ads ran for Eritrea (\#26), Serbia (\#12) and Ukraine (\#18).

\section{(b) Creating affinity with the destination}

Here the marketers tried to give American and British audiences a feeling of geographical proximity to the marketed destination. In these messages the ads didn't just mention the place's location but emphasized its closeness to the target audience. Some examples were: Shetland on your doorstep (NGT 5/2014); Missouri - Close to home, far from ordinary (CNT 3/2008); Azores - 'Less than a four-hour flight from the United Kingdom' (NGT 10/2019); Belize - 'Located only two hours from the US' (\#3); 'Canada - The wonderful world at your doorstep' and 'Litchfield Hills: Just down the road' (NGT 9/2008); and 'North Sardinia, just a stone's throw away' (NGT 4/2015). Here the frequent use of the word 'only' was intentional and emphasized how 'close' the destination was to the target audience's home and that it 'is not as far as you think'. Not only was the destination's nearness emphasized, but the number of possible flights was also highlighted. For example, 'Malta: flights 
from Gatwick, Heathrow ... and 18 more airports' (NGT 9/2014); 'Nineteen flights a week from Edinburgh and Glasgow to Copenhagen' (NGT 5-6/2011); 'British airways flies into Kingston 3 times a week' (\#24). The main technique in this strategy is geographical proximity.

\subsection{The economic sphere}

An additional sphere that marketers use to present a destination and create affinity is economic. The economic sphere deals with all the financial aspects of tourism and combines factors such as tourist cost, currency and investment. Several studies that explore bases for consumer affinity find that these economic components are central (Oberecker et al. 2008; Souiden et al. 2017).

\subsubsection{Tourist costs and currency}

The importance of tourist costs and currency is well known as part of almost every interaction in a visit. In this component we can find ads where marketers publish information about prices for tourist services as a way of creating affinity with a certain audience.

\section{(a) Describing the destination's characteristics}

Here the marketers present the cost of flights and holiday packages in the destination's currency; the local currency is used in the ads like all the other destination characteristics. The local currency, and its low exchange rate, can also be used to indicate a bargain, making the destination attractive for tourists. Examples include: 'Ireland, island of 100,000 welcomes. At some very friendly prices' (NGT 3/2009); 'Take a vacation for less in Missouri' (NGT 3/2008); and Ukraine - 'Most affordable tourist destination in Europe' (\#18).

\section{(b) Creating affinity with the destination}

As opposed to the use of the local currency in an ad, marketers can use the target audience's home currency. We believe that this can create affinity and make the destination 'closer' to the target audience. For example, Barbados and Singapore DMOs, together with British Airways, advertised packages to these countries in British pounds (NGT 7-8/2014) and Singapore offered 'a stopover holiday at a price of 19 pounds' (NGT 3/ 2015); Samoa's ad offered '5 nights from $£ 495$ ' (NGT 4/2014); Myanmar's ad offered 'prices from $£ 1640$ per person' (NGT 8/2010); and Japan's 'Enjoy my Japan' ad had the main headline 'London to Japan: from £549 return' (NGT 10/ 2019). Finally, the use of tax abatement alongside currency is another way of creating affinity: Gibraltar's slogan was 'Sterling area; Vat-free shopping' (NGT 4/2014).

\subsubsection{Attracting investment}

In this component marketers try to use tourism as a trigger to attract investment. In order to do this, marketers publish information and economic data about the place. 
According to Nes et al. (2014: 777), 'positive or negative association with a country may be caused by impressions of a country's economic system'.

\section{(a) Describing the destination's characteristics}

Besides currency, marketers also emphasize the destination's financial and economic achievements, as ads are aimed at tourists and investors. The campaign for Bulgaria was a good example to show the connection between tourism and economy as the main slogan was 'Come for a visit, return on investment' (\#23), which emphasized many of the country's characteristics such as easy access to main markets, lower government deficits and a skilled workforce. India's campaign was also a good example, emphasizing its economic achievement, and Georgia did the same (\#15).

\section{(b) Creating affinity with the destination}

In order to present similarity and create affinity while attracting investment we found interesting, creative examples from Eastern European countries. In a video to attract investment in the tourism industry, Croatia used its ambassador to the UK, who described the country's goals in the field of tourism development (\#17). Also, to attract British investment in Kosovo, the latter's ad had the main male Kosovan actor mention that his favourite football team was Liverpool: 'My most important thing that makes my day perfect is when my favourite team, Liverpool, wins a game' (\#34). Kosovo similarly used former UK Prime Minister Tony Blair and former US First Lady Hillary Clinton in another ad that also tried to attract investment (\#33).

\section{DISCUSSION AND CONCLUSIONS}

This study analyses how international and local marketers tried to create affinity between tourist destinations and audiences, and offers a theoretical framework factors involved in creating affinity between destinations and target audiences in tourism ads - which includes four spheres, two message strategies and five techniques. Although this study is not based on empirical research, it suggests ways to improve the chances of creating affinity through advertising. We believe that its importance stems from its reliance on previous empirical studies, which found that the framework's factors did in fact create affinity between audiences and destinations. Advertisers who want to optimize their destination's advertising and improve the likelihood of increasing the affinity between their destination and specific audiences can find this theoretical framework helpful.

O'Barr (1994: 12) argues that advertisements lay down templates from which Americans (and others) construct images of others and judge relations with them. That is, advertising can help create affection or fondness as well as closer relationships between product and audience. This insight is especially critical in tourism marketing, where the product is less tangible (Fyall et al. 2019). Since people tend to prefer other people who are similar or close to themselves, with whom they share the same values and culture, it is only natural for tourism marketers to emphasize this proximity, familiarity or similarity to increase the effectiveness of the marketing process (Bekk et al. 2016; Avraham/ Ketter 2008). It is not that such an attempt has not been made by the foreign 
destinations' advertisers, since the use of advertisements aimed at American and British audiences in the English language is already an attempt to create affinity with these audiences. Nevertheless, of the thousands of advertisements and hundreds of YouTube videos analysed for this study, only in a small number did we find any attempt to create a connection between the destination and the American or British audience. Interestingly, this was true in both print and video advertisements.

We believe that marketers of many destinations would benefit if they increased their efforts to find and emphasize the unique relationship, closeness, previous familiarity or proximity between the marketed destination and specific audiences that might differentiate it from other destinations. This is also necessary in light of the tourism industry's expected future competition and the search for new customers in the postCOVID-19 era. This search for a sense of belonging (Fyall et al. 2019), as well as other factors examined in previous empirical affinity studies, can be of great help in creating affection and affinity between audiences and destinations (Nes 2019; Nes at al. 2014; Oberecker et al. 2008; Souiden et al. 2017; Bekk et al. 2016; Asseraf/Shoham 2017). Abraham Lincoln once said, 'Give me six hours to chop down a tree and I will spend the first four sharpening the axe.' Similarly, marketers must undertake serious preparation, learning about their target audiences in depth before launching campaigns to create affinity and improve the efficiency of advertisements (Jiang et al. 2020; Collins-Kreiner et al. 2018). The more familiar marketers are with the cultural, national, geographical and economic characteristics of the target audience, the greater the chances of producing ads that will create affinity with the target audience.

We believe that the novelty of the suggested theoretical framework is the presentation of two message strategies. Because the image of a destination, as mentioned, contains three characteristics - cognitive, emotional and evaluative (Boulding 1956) - an advertiser using the message strategy describing the destination's characteristics conveys information about the destination to a target audience and enriches the cognitive characteristic of the place's image. However, when marketers convey information about a place using the message strategy creating affinity with the destination, while showing the similarity between a place and the target audience, they touch on both the emotional and the evaluative characteristics of a place's image. Ensuring that the marketing messages align with all of the target audience's image characteristics of a place helps greatly in creating a rich image and the chance to create affinity with the target audience (Boulding 1956; Kim/Lehto 2013).

The theoretical framework presented here has practical implications for marketers, in addition to theoretical ones. Successful marketing, especially during the current era, requires creating affinity with specific target audiences for several reasons. First, the consumer has become accustomed to personal marketing and direct messaging, mainly through new media. This development actually foreshadows the end of general marketing and the era in which advertisements were addressed to all target audiences (Frochot/Batat 2013). At the same time, according to Hudson and Ritchie (2009), tourism marketing is becoming more and more 'experiential marketing'. The tendency to show not only landscapes in ads, but culture and history as well, creates a combination of spheres, strategies and techniques (Hudson/Ritchie 2009; Frochot/Batat 2013). Marketers can learn a great deal from the model offered here about the possibilities of creating affinity with target audiences at the national and international levels.

A strong case study for examining our theoretical framework can be made with two videos run by Mexico in 2017 aimed at British and American audiences. 
In the video for UK visitors (\#41) the marketers used three spheres (cultural, geographical and national), four techniques (proximity, similarity, familiarity and cultural brands) and two message strategies. Here is part of the narrator's text, with the spheres (and their components) and the techniques added:

Dear UK, You and I have a lot in common [proximity]; we are both moved by music, majestic stages [cultural sphere, music component, similarity] and historic theatres [national sphere, history] ... We are loyal to our flavors with yours as sophisticated as your whisky [cultural sphere, cuisine] and as inexplicable as the taste of our tequila, but nobody celebrate a goal like you and me [cultural sphere, sport, similarity] ... I will never forget that you were the first one to truly value me [geographical sphere, sights, familiarity] ... You and I would agree that we could transcend this world together. Your friend, Mexico.

In addition, the narrator was speaking English (national sphere, language) and the video showed the British and Mexican flags (national sphere, flag), tourist sights and places in both countries (geographical sphere, sights), and mentioned English tea and (Scotch) whisky (cultural sphere, cuisine). Mentioning both Mexican and UK characteristics shows how the 'describing the destination's characteristics' message strategy can turn an ad into the 'creating affinity with the destination' strategy. The use of such a large number of spheres, techniques and message strategies in this ad illustrates the many possibilities that exist in a video campaign to create affinity compared to a printed ad, which is much more limited due to the nature of the print medium. A similar Mexican tourism ad for the American market presents the American flag, famous US sights such as the Statue of Liberty and the Las Vegas Strip, and stresses that 'We share our common values' (\#42).

Despite the increase in the number of Americans holding passports and travelling abroad in recent years, it can still be said that America's outbound tourism market has not yet exhausted its potential. There are several reasons for this. First is the country's size and variety of sights, landscapes and tourist niches (for example beaches, desert, snow; adventure and nature tourism), which makes many Americans feel there is no need to vacation abroad. Second is fear of a world that is perceived as threatening, a feeling that grew after 9/11. Third, Americans are not particularly interested in the outside world; this is expressed in under-developed world geography studies in the US and a media that hardly deals with international news. Fourth is the relatively high cost of international travel; and fifth is the average small number of paid vacation days (Kepnes 2017; Alden 2017; Avraham/Ketter 2016). Even when Americans travel to foreign destinations, they tend to remain close to home. For example, in 2018 the number of tourists travelling abroad was 93 million; 51.3 million travelled to destinations in North America (Mexico and Canada) and 41.8 million to the rest of the world (Silk 2019). In any case, it seems that some marketers around the world have realized that American tourists must overcome a relatively large number of barriers before making the decision to travel abroad. This, in turn, causes the marketers to send this audience reassuring messages.

There is a need to mention the limitations of this study. When using the 'factors involved in creating affinity between destinations and target audiences in tourism ads' model to analyse ads it should be remembered that the division into spheres, appeal strategies and means was done mainly for academic analysis. This analysis has its challenges. The language component can belong to both the sphere of culture and the national sphere (First/Avraham 2009). Another challenge is the limitation of the study mainly to ads in English. Language, as we know, is much more than just a means to communicate; it also has wholly social-political-cultural aspects. In our case we expect the effect of 
the Western/Anglo-Saxon environment on our analysis. It is possible that in other languages (and other social-political-cultural environments) the model's factors might be weighted differently. There are some options for future research here. First and foremost is an empirical experiment that will present ads to British and American audiences and try to find which combination of the model's factors, based on our suggested theoretical framework, will create stronger affinity for local and foreign tourism destinations. In addition, quantitative content analysis studies on the various factors of the current theoretical framework can examine changes over the years in attempts to create affinity between various destinations among the same audiences. For example, which factors have Caribbean destinations used to build affinity with the American public over the years, and have these factors changed over time?

\section{REFERENCES}

Alden, N. (2017): Why don't Americans travel internationally?, HuffPost, 6 December 2017, URL: https://www.huffpost.com/entry/why-dont-americans-travel_b_9214256 (accessed 20 October 2019).

Asseraf, Y., Shoham, A. (2017): Destination branding: the role of consumer affinity, in: Journal of Destination Marketing and Management, 6(4), 375-384.

Avraham, E. (2016): Destination marketing and image repair during tourism crises: the case of Egypt, in: Journal of Hospitality and Tourism Management, 28, 41-48.

Avraham, E. (2020): Nation branding and marketing strategies for combatting tourism crises and stereotypes toward destinations, in: Journal of Business Research, 116, 711-720.

Avraham, E. (2021): Combating tourism crisis following terror attacks: image repair strategies for European destinations since 2014, in: Current Issues in Tourism, 24(8), 1079-1092.

Avraham, E., Ketter, E. (2008): Media Strategies for Marketing Places in Crises: Improving the Image of Cities, Countries, and Tourist Destinations, Oxford: Butterworth Heinemann.

Avraham, E., Ketter, E. (2016): Tourism marketing for Developing Countries: Battling Stereotypes and Crises in Asia, Africa and the Middle East, London: Palgrave Macmillan.

Baloglu, S., McCleary, K.W. (1999): A model of destination image formation, in: Annals of Tourism Research, 26(4), 868-897.

Bekk, M., Spörrle, M., Kruse, J. (2016): The benefits of similarity between tourist and destination personality, in: Journal of Travel Research, 55(8), 1008-1021.

Boulding, K.E. (1956): The Image: Knowledge in Life and Society, Ann Arbor: University of Michigan Press.

Brito, P.Q., Pratas, J. (2015): Tourism brochures: linking message strategies, tactics and brand destination attributes, in: Tourism Management, 48, 123-138.

Cahill, D.J. (1997): Target marketing and segmentation: valid and useful tools for marketing, in: Management Decision, 35(1), 10-13.

Cheung, Y.H.Y., Saha, S. (2015): Exploring the nexus between tourism demand and cultural similarity, in: Tourism Analysis, 20(2), 229-241.

Collins-Kreiner, N., Yonay, Y., Even, M. (2018): Backpacking memories: a retrospective approach to the narratives of young backpackers, in: Tourism Recreation Research, 43(3), $409-412$.

d'Astous, A., Boujbel, L. (2007): Positioning countries on personality dimensions: scale development and implications for country marketing, in: Journal of Business Research, 60(3), 231-239.

De Jager, A.E. (2010): How dull is Dullstroom? Exploring the tourism destination image of Dullstroom, in: Tourism Geographies, 12(3), 349-370.

Echtner, C.M., Ritchie, J.B. (1993): The measurement of destination image: an empirical assessment, in: Journal of Travel Research, 31(4), 3-13.

First, A., Avraham, E. (2009): America in JeruSALEm: Globalization, National Identity, and Israeli Advertising, Lanham, MD: Lexington Books. 
Fourie, J., Santana-Gallego, M. (2013): Ethnic reunion and cultural affinity, in: Tourism Management, 36, 411-420.

Frochot, I., Batat, W. (2013): Marketing and Designing the Tourist Experience, Oxford: Goodfellow.

Fyall, A., Legohérel, P., Frochot, I., Wang, Y. (2019): Marketing for Tourism and Hospitality: Collaboration, Technology and Experiences, Abingdon, UK: Routledge.

Hartz, A., Watson, D.C., Noyes, R. (2005): Applied study of affinities for personal attributes using an epidemiological model, in: Social Behavior and Personality, 33(7), 635-50.

Hudson, S., Ritchie, J.R.B. (2009): Branding a memorable destination experience: the case of 'Brand Canada', in: International Journal of Tourism Research, 11(2), 217-228.

Jiang, H., Tan, H., Liu, Y., Wan, F., Gursoy, D. (2020): The impact of power on destination advertising effectiveness: the moderating role of arousal in advertising, in: Annals of Tourism Research, 83, 102926.

Kepnes, M. (2017): Why Americans don't travel overseas, Nomadic Matt blog, 10 October, URL: https://www.nomadicmatt.com/travel-blogs/why-americans-dont-travel-overseas (accessed 10 November 2019).

Ketter, E., Avraham, E. (2021): \#StayHome today so we can \#TravelTomorrow: tourism destinations' digital marketing strategies during the Covid-19 pandemic, in: Journal of Travel and Tourism Marketing, 1-14.

Kim, S., Lehto, X.Y. (2013): Projected and perceived destination brand personalities: the case of South Korea, in: Journal of Travel Research, 52(1), 117-130.

Kotsi, F., Balakrishnan, M.S., Michael, I., Ramsøy, T.Z. (2018): Place branding: aligning multiple stakeholder perception of visual and auditory communication elements, in: Journal of Destination Marketing and Management, 7, 112-130.

Lai, M.Y., Wang, Y., Khoo-Lattimore, C. (2020): Do food image and food neophobia affect tourist intention to visit a destination? The case of Australia, in: Journal of Travel Research, 59(5), 928-949.

Mair, J., Ritchie, B.W., Walters, G. (2016): Towards a research agenda for post-disaster and post-crisis recovery strategies for tourist destinations: a narrative review, in: Current Issues in Tourism, 19(1), 1-26.

Nes, E.B. (2019): The role of country images in international marketing: country-of-origin effects, in: Nes, E.B. (ed.), Bridging Disciplinary Perspectives of Country Image Reputation, Brand, and Identity, New York: Routledge, 49-64.

Nes, E.B., Yelkur, R., Silkoset, R. (2014): Consumer affinity for foreign countries: construct development, buying behavior consequences and animosity contrasts, in: International Business Review, 23(4), 774-784.

New Yorkled (2016): International consulates/diplomatic missions in New York City: list and maps, URL: https://www.newyorkled.com/international-consulates-diplomatic-missions-innew-york-city-list-and-maps (accessed 10 November 2019).

O'Barr, W.M. (1994): Culture and the Ad: Exploring Otherness in the World of Advertising, Boulder, CO: Westview.

Oberecker, E.M., Riefler, P., Diamantopoulos, A. (2008): The consumer affinity construct: conceptualization, qualitative investigation, and research agenda, in: Journal of International Marketing, 16(3), 23-56.

Pauly, J. (1991): A beginner's guide to doing qualitative research in mass communication, in: Journalism Monographs, 125, 1-29.

Rinaldi, C., Beeton, S. (2015): Success in place branding: the case of the Tourism Victoria Jigsaw Campaign, in: Journal of Travel and Tourism Marketing, 32(5), 622-638.

Silk, R. (2019): Americans' overseas travel surged in 2018, Travel Weekly, 3 April, URL: https://www.travelweekly.com/Travel-News/Airline-News/Americans-overseas-travelsurged-in-2018 (accessed 20 November 2019).

Souiden, N., Ladhari, R., Chiadmi, N.E. (2017): Destination personality and destination image, in: Journal of Hospitality and Tourism Management, 32, 54-70. 
Stepchenkova, S., Li, X.R. (2014): Destination image: do top-of-mind associations say it all?, in: Annals of Tourism Research, 45, 46-62.

Tuchman, G. (1991): Qualitative methods in the study of news, in: Jensen, K.B., Jankowski, N.W. (eds), A Handbook of Qualitative Methodologies for Mass Communication Research, London: Routledge, 79-92.

Van Dijk, T.A. (1988): News As Discourse, Hillsdale, NJ: Lawrence Erlbaum.

Walters, G., Clulow, V. (2010): The tourism market's response to the 2009 Black Saturday bushfires: the case of Gippsland, in: Journal of Travel and Tourism Marketing, 27(8), 844-857.

Walters, G., Mair, J. (2012): The effectiveness of post-disaster recovery marketing messages: the case of the 2009 Australian bushfires, in: Journal of Travel and Tourism Marketing, 29(1), 87-103.

Zimet, D. (2017): Nation and place Branding in a Competitive World, Tel-Aviv: Steimatzky. 


\section{APPENDIX 1}

Table Al Links to YouTube videos mentioned in the manuscript

\begin{tabular}{|c|c|c|}
\hline Ad. No & Country/State & Link \\
\hline 1 & Australia & https://www.youtube.com/watch?v=Xn_CPrCS8gs \\
\hline 2 & Albania & https://www.youtube.com/watch?v=vd14e-KC-rk \\
\hline 3 & Canada & https://www.youtube.com/watch?v=YRN1ddB75eI \\
\hline 4 & Australia & https://www.youtube.com/watch?v=WP-39Qq4OQc \\
\hline 5 & Holland & https://www.youtube.com/watch?v=hqEh0iFWlgs \\
\hline 6 & Philippines & https://www.youtube.com/watch?v=U-a6yOp0CyI \\
\hline 7 & Philippines & https://www.youtube.com/watch?v=U-a6yOp0CyI \\
\hline 8 & Holland & https://www.youtube.com/watch?v=GlOu7MJALQ4 \\
\hline 9 & Laos & https://www.youtube.com/watch?v=U-a6yOp0CyI \\
\hline 10 & Thailand & https://www.youtube.com/watch?v=U-a6yOp0CyI \\
\hline 11 & Kosovo & https://www.youtube.com/watch?v=AVsGm0HvNbg \\
\hline 12 & Serbia & https://www.youtube.com/watch?v=XEpUrhGvBo0 \\
\hline 13 & Belize & https://www.youtube.com/watch?v=V_bmmoHZbJk \\
\hline 14 & Indonesia & https://www.youtube.com/watch?v=U-a6yOp0CyI \\
\hline 15 & Georgia & https://www.youtube.com/watch?v=w7A5YspSOFQ \\
\hline 16 & Croatia & https://www.youtube.com/watch?v=qTjsepKI $1 j w \& t=36 \mathrm{~s}$ \\
\hline 17 & Croatia & https://www.youtube.com/watch?v=BzPgsKDc2mw \\
\hline 18 & Ukraine & https://www.youtube.com/watch?v=MieNulvmgZg \\
\hline 19 & Visit England & https://www.youtube.com/watch?v=k_oDI_qyAHo \\
\hline 20 & Colombia & https://www.youtube.com/watch?v=qgW8Y7F8DN8 \\
\hline 21 & Canada & https://www.youtube.com/watch?v=8uYV40SyfQs \\
\hline 22 & Curacao & https://www.youtube.com/watch?v=jsFBwwHy44c \\
\hline 23 & Bulgaria & https://www.youtube.com/watch?v=9i1IVCD8VzA \\
\hline 24 & Jamaica & https://www.youtube.com/watch?v=H4Xlj3dz1Qo \\
\hline 25 & Sierra Leone & https://www.youtube.com/watch?v=PDrtnhbSOIQ \\
\hline 26 & Eritrea & https://www.youtube.com/watch?v=VjvgcvkD600 \\
\hline 27 & Tunisia & https://www.youtube.com/watch?v=cR8mH08xNVw \\
\hline 28 & Lebanon & https://www.youtube.com/watch?v=Z_cxqA5qYbU \\
\hline 29 & Portugal & https://www.youtube.com/watch?v=10J04RovaGg \\
\hline 30 & Barbados & https://www.youtube.com/watch?v=zOFJQ3hKmco \\
\hline 31 & Barbados & https://www.youtube.com/watch?v=-7TtY_kTbD8 \\
\hline 32 & South Africa & https://www.youtube.com/watch?v=EZztihHOB6g \\
\hline 33 & Kosovo & https://www.youtube.com/watch?v=SWSnGtIYSjc \\
\hline 34 & Kosovo & https://www.youtube.com/watch?v=1EIonehrv8M \\
\hline 35 & Visit Britain & https://www.youtube.com/watch?v=9hL9yDOK48A \\
\hline 36 & Tunisia & https://www.youtube.com/watch?v=izQqZEEy1cU \\
\hline 37 & Mexico & https://www.youtube.com/watch?v=98Kj7ZKz1S0 \\
\hline 38 & Zambia & https://www.youtube.com/watch?v=I60zL2xZO9M \\
\hline 39 & Egypt & https://www.youtube.com/watch?v=jCdoHRR4JB8 \\
\hline 40 & Japan & https://www.youtube.com/watch?v=WLIv7HnZ_fE \\
\hline 41 & Mexico & https://www.youtube.com/watch?v=t_zc84SeAdY \\
\hline 42 & Mexico & $\begin{array}{l}\text { https://www.youtube.com/watch? } \mathrm{v}=\mathrm{uKrhLOLing} Y \& \text { list=RDCMUC- } \\
\text { VgICY7Wt5Yu4hdo02ACXA\&index=9 }\end{array}$ \\
\hline
\end{tabular}

